\title{
Publisher Correction: Liquid phase blending of metal-organic frameworks
}

Louis Longley ${ }^{1}$, Sean M. Collins (1) ${ }^{1}$, Chao Zhou (1) ${ }^{2}$, Glen J. Smales ${ }^{3,4}$, Sarah E. Norman ${ }^{5}$, Nick J. Brownbill ${ }^{6}$, Christopher W. Ashling', Philip A. Chater (1) ${ }^{4}$, Robert Tovey (1) ${ }^{7}$, Carola-Bibiane Schönlieb ${ }^{7}$, Thomas F. Headen ${ }^{5}$, Nicholas J. Terrill (10) 4, Yuanzheng Yue ${ }^{2,8,9}$, Andrew J. Smith (1) 4, Frédéric Blanc (10) 6,10, David A. Keen (10) ${ }^{5}$, Paul A. Midgley ${ }^{1} \&$ Thomas D. Bennett (1) ${ }^{1}$

Correction to: Nature Communications https://doi.org/10.1038/s41467-018-04553-6; published online 15 June 2018

The original version of this Article contained an error in Fig. 1b, where the blue '(ZIF-4-Zn $)_{0.5}(\text { ZIF-62 })_{0.5}$ blend' data curve was omitted from the enthalpy response plot. This has now been corrected in both the PDF and HTML versions of the Article.

Published online: 18 October 2018

\begin{abstract}
(c) (i) Open Access This article is licensed under a Creative Commons Attribution 4.0 International License, which permits use, sharing, adaptation, distribution and reproduction in any medium or format, as long as you give appropriate credit to the original author(s) and the source, provide a link to the Creative Commons license, and indicate if changes were made. The images or other third party material in this article are included in the article's Creative Commons license, unless indicated otherwise in a credit line to the material. If material is not included in the article's Creative Commons license and your intended use is not permitted by statutory regulation or exceeds the permitted use, you will need to obtain permission directly from the copyright holder. To view a copy of this license, visit http://creativecommons.org/licenses/by/4.0/.
\end{abstract}

(c) The Author(s) 2018

\footnotetext{
${ }^{1}$ Department of Materials Science and Metallurgy, University of Cambridge, Charles Babbage Road, Cambridge CB3 OFS, UK. ${ }^{2}$ Department of Chemistry and Bioscience, Aalborg University, DK-9220 Aalborg, Denmark. ${ }^{3}$ Department of Chemistry, University College London, Gordon Street, London WC1H OAJ, UK. ${ }^{4}$ Diamond Light Source Ltd, Diamond House, Harwell Science and Innovation Campus, Didcot OX11 ODE, UK. ${ }^{5}$ ISIS Facility, Rutherford Appleton Laboratory, Harwell Campus, Didcot OX11 OQX, UK. ${ }^{6}$ Department of Chemistry, University of Liverpool, Crown Street, Liverpool L69 7ZD, UK. ${ }^{7}$ Department of Applied Mathematics and Theoretical Physics, Centre for Mathematical Sciences, Wilberforce Road, Cambridge CB3 OWA, UK. ${ }^{8}$ State Key Laboratory of Silicate Materials for Architectures, Wuhan University of Technology, 430070 Wuhan, China. ${ }^{9}$ School of Materials Science and Engineering, Qilu University of Technology, 250353 Jinan, China. ${ }^{10}$ Stephenson Institute for Renewable Energy, University of Liverpool, Crown Street, Liverpool L69 7ZD, UK. Correspondence and requests for materials should be addressed to T.D.B. (email: Tdb35@cam.ac.uk)
} 